\title{
Dyadic coping, quality of life, and psychological distress among chronic obstructive pulmonary disease patients and their partners
}

This article was published in the following Dove Press journal:

International Journal of COPD

16 November 2011

Number of times this article has been viewed

Caroline Meier'

Guy Bodenmann²

Hanspeter Mörgeli'

Josef Jenewein'

'Department of Psychiatry and Psychotherapy, University Hospital Zurich, Switzerland; '2Institute of Psychology, University of Zurich, Switzerland
Correspondence: Caroline Meier Consultation and Liaison Psychiatry, Department of Psychiatry and Psychotherapy, University Hospital Zurich, Raemistrasse 100, CH-809/ Zurich, Switzerland

Tel +4I 442559700

Fax +4| 44255970 I

Email caro2579@yahoo.com
Background: Successfully coping with a chronic disease depends significantly on social support, particularly that of a significant other. Thus, it depends on the ways of dealing with stress within a couple (dyadic coping). In this study, the relationship between dyadic coping and well-being was investigated among couples in which one partner suffers from chronic obstructive pulmonary disease (COPD).

Methods: A total of 43 couples participated. They were mailed questionnaires on anxiety and depression (Hospital Anxiety and Depression Scale), quality of life (World Health Organization Quality of Life Questionnaire-BREF), and dyadic coping (Dyadic Coping Inventory).

Results: Low scores of positive and high scores of negative dyadic coping were associated with poorer quality of life and higher psychological distress among couples. Delegated coping (assistance with daily tasks) was higher among partners. When estimated by patients, high delegated partner coping (frequent provision of support by partners) and low delegated personal coping (low provision of support by patients) were associated with poorer quality of life for both patient and partner. COPD patients suffering from depression were supported more often and attributed deficits in dyadic coping primarily to themselves, whereas partners with higher scores of depression provided higher estimates of both their own negative coping and the negative coping of their partner.

Conclusion: The higher the patient perceived the imbalance in delegated dyadic coping, the lower the couple's quality of life. More negative and less positive dyadic coping were associated with lower quality of life and higher psychological distress. Psychotherapeutic interventions to improve dyadic coping may lead to better quality of life and less psychological distress among COPD patients and their partners.

Keywords: COPD, dyadic coping, partner study, quality of life, anxiety, depression

\section{Introduction}

Receiving support from a partner acquires great importance when coping with a chronic disease like chronic obstructive pulmonary disease (COPD). ${ }^{1-4}$ Partners are typically patients' most important caregivers and are most often looked to for support. ${ }^{4,5}$ The quality of support from the partner and thus the partner's own well-being play a crucial role in patients' ability to cope with their disease. ${ }^{6}$

COPD is characterized by irreversible, progressive obstruction of airways. ${ }^{7}$ Its prevalence and corresponding mortality are expected to increase significantly in the coming decades. ${ }^{8}$ Not only is COPD associated with many physical symptoms but also it is a considerable source of psychological distress. ${ }^{9,10}$ Compared with patients suffering from other chronic diseases, COPD patients display a high degree of psychological distress $^{11}$ such as anxiety and depression. ${ }^{8,10,12,13}$ 
In addition to its significant influence on patients' psychological health, COPD mirrors other chronic diseases in having an effect on patients' social environment, in particular on their partner. ${ }^{5,10,13}$ Psychological symptoms such as anxiety, depression, and feelings of helplessness are frequently reported in the literature on partners of COPD patients. ${ }^{8}{ }^{82,14}$ Above all, patients' breathing problems are usually very stressful for partners. ${ }^{14,15}$ Patients' dyspnea reduces their vitality, increases their dependency, and leads to changes in roles. Partners often take responsibility for tasks that patients used to do themselves, such as looking after the household, finances, or physical care. ${ }^{5,10,16}$ Furthermore, partners face societal expectations that they care for their ill partner. In the case of a chronic disease, this means acting as a caregiver for the rest of the ailing partner's life - a considerable practical and emotional burden for partners. ${ }^{5}$

The way in which a couple deals with a chronic disease may be analyzed either on an individual level - from the separate points of view of patient and partner - or as a dyadic process that considers both partners' (patient and partner) mutual influence on each other, according to their ways of dealing with stress individually and in relation to each other. The latter form of stress management is called dyadic coping. ${ }^{17,18}$

Dyadic coping aims to maintain or restore individual and dyadic homeostasis, both partners' well-being, and the couple's functioning. ${ }^{18}$ Individuals who provide adequate supportive dyadic coping to their partner may themselves benefit. Relieving their burden contributes to greater closeness and, over time, a positive cognitive representation of the partner is built, covarying with attributions of helpfulness and trustworthiness. Thus, dyadic coping improves mutual trust, security, and intimacy, exerting a positive influence on the relationship and benefiting both partners. ${ }^{1}$

Bodenmann ${ }^{18}$ distinguishes four forms of dyadic coping: positive supportive dyadic coping (support provided by one partner in an attempt to assist the other partner in his or her coping efforts), delegated dyadic coping (one partner asks the other to take over certain tasks and duties in an effort to reduce his or her stress experienced in the situation), common dyadic coping (both partners participate in the coping process more or less symmetrically), and negative dyadic coping (superficial, ambivalent, or hostile support provision). Especially in distressed couples or in the context of mental disorders or chronic illness, ambivalent or hostile dyadic coping has been shown to occur with greater frequency. ${ }^{19}$

In negative dyadic coping, partners support their counterpart in a disapproving, uninspired, or patronizing way.
Although the partner provides support to their counterpart, a negative underlying tone predominates and is usually perceived by the recipient of support. In other cases, one partner may underestimate the other's abilities (especially in the context of psychological or physical disorders) and try to take responsibility for everything, diminishing the intended beneficiary's feeling of self-efficacy. ${ }^{10}$ Thus, positively intended dyadic coping may be dysfunctional in couples in which one partner is disabled or chronically ill, when forms of excessive kindness, concern, and support paralyze efforts by the patient. ${ }^{20}$

In a study of coping among couples where one partner suffered from asthma, it was shown that overprotection and protective buffering increase the burden of both patient and partner. ${ }^{21}$ Among patients suffering from various illnesses associated with breathing difficulties (COPD, heart disease, lung cancer, or motor neuron disease), it has generally been shown that their partners tend toward overprotection, that their partners suffer from their great responsibility, and that it is better for both individuals when responsibility for the patient's care and well-being does not rest solely with the partner. In order to handle such illnesses, it appears important that affected couples are given professional support to reduce their sense of isolation and that partners are not made to be solely responsible for all the couple's tasks, but rather that responsibilities are deliberately divided up..$^{15}$

The chronic disease COPD is a considerable source of distress for patients and their partners. The corresponding stress can negatively affect their dyadic coping. ${ }^{22}$ Conversely, dyadic coping can reduce the negative impact of stress on a relationship (unpublished data, Peter-Wight et al).

Various studies have demonstrated that the extent and quality of couples' dyadic coping correlate with their levels of psychological well-being and the quality of their relationship (eg, psychological disorders, well-being, marital quality). ${ }^{1,24}$ Depressed patients, for example, perceive less positive coping and more negative coping in their partners; however, when assessing their own dyadic coping, such patients have been shown to be indistinguishable from a control group. ${ }^{19,25}$ In addition, a significant correlation $(r=0.31)$ has been found between anxiety and negative dyadic coping. ${ }^{24}$

To our knowledge, no research has been done on dyadic coping among COPD patients. The present study sought to examine the relationship between dyadic coping and quality of life/psychological distress among COPD patients and their partners.

We expected that higher positive and lower negative dyadic coping would be associated with higher quality of 
life and lower psychological distress among patients as well as partners. Further, we assumed that patients receive more support from their partners than vice versa. According to expectations, this imbalance should be more noticeable in cases where the patient is suffering from severe psychological distress.

\section{Method \\ Procedure}

In a cross-sectional study, quantitative data from COPD patients and partners were examined. All patients had established contact with the Zurich Lung League, Switzerland.

The data were collected using questionnaires. Patients were mailed a patient questionnaire and a partner questionnaire. These were accompanied by a letter requesting that patients and partners complete and return their questionnaires independent of each other. In cases where the patient did not have a partner, he or she was requested to complete and return the patient questionnaire only. The data of those patients were not included in calculations for the study.

By signing an enclosed consent form, patients and partners agreed to the terms of the study. If the questionnaire was not completed and returned within 28 days, patients were sent a letter of reminder.

Lung function was measured in a standardized manner using spirometry. This method enables calculation of the forced expiratory volume in 1 second $\left(\mathrm{FEV}_{1}\right)$ score. The $\mathrm{FEV}_{1}$ score represents the amount (volume) of air exhaled in the first second of the FEV measurement. This value is the most important parameter of lung function testing. In order to assess the severity of patients' COPD according to the Global Initiative for Chronic Obstructive Lung Disease (GOLD), ${ }^{26}$ their respective attending physician was contacted and asked to provide the patient's most recent measurement of lung function. Lung functioning of patients undergoing oxygen treatment must be measured at least once per year in order to determine their oxygen needs and adjust their equipment accordingly. For the sake of our study, patients' most recent $\mathrm{FEV}_{1}$ score was used, measured no more than 1 year prior to our survey.

The present study was approved and accepted by the Canton of Zurich's ethics committee.

\section{Participants}

Questionnaires were mailed to 550 COPD patients who were receiving regular care from the Zurich Lung League. To participate in the study, patients had to fulfill the following criteria for inclusion: COPD diagnosis, receiving care from the Zurich Lung League, minimum age 40 years (to reduce the likelihood of mistakenly including asthma patients), maximum age 85 years, sufficient knowledge of German to complete the questionnaire, adequate health to complete the questionnaire independently, and living in a committed relationship.

Of 550 patients contacted, 151 were excluded as they did not fulfill the inclusion criteria. Reasons for exclusion were the following: the patient was no longer a member of the Zurich Lung League ( $\mathrm{n}=36)$, inadequate health to complete the questionnaire independently $(n=34)$, insufficient knowledge of German $(n=31)$, patient deceased $(n=22)$, no diagnosis of COPD (according to the patient) $(n=12)$, severely impaired vision $(n=7)$, invalid address $(n=5)$, suffering from Alzheimer's disease $(n=2)$, required the support of a legal guardian $(n=1)$, and suffering from schizophrenia $(n=1)$.

Of the 399 remaining patients, 97 agreed to participate in the study. Further, 54 partners completed and returned the partner questionnaire. This yielded a total of 43 complete couples, 54 individual patients, and eleven individual partners. This corresponds to a response rate of $24.3 \%$ among patients.

Our sample of 43 couples is too small to establish a generalizable relationship between dyadic coping, quality of life, and psychological distress. An analysis of statistical power was carried out. For the expected strength of association of $r=0.3, \mathrm{n}=81$ couples would be required to achieve a statistical power of $80 \%$ with a two-sided $\alpha$ of 0.05 . Our study of 43 couples has a power of $52 \%$. Due to our small sample, certain correlations may have been missed (Type II error). For this reason, we did not correct the $\alpha$ according to Bonferroni, despite repeated measures. In our study, quality of life was measured according to five dimensions, whereas dyadic coping was measured according to 15 dimensions. If we were to correct the level of significance according to Bonferroni ${ }^{27}(P=0.05 / 75)$, a correlation would only be significant when $P<0.0007$. Were the $\alpha$ corrected according to Bonferroni, we would need 186 couples to achieve a statistical power of $80 \%$ with the expected strength of association of $r=0.3$, something that would be very difficult to achieve with couples' data from this type of hard-to-reach population sample. In general, the Bonferroni correction is often described in the literature as being very conservative, and it is criticized for making the likelihood too great that a Type II error will occur when a false null hypothesis fails to be rejected. ${ }^{28-30}$ Had we corrected the $\alpha$ according to Bonferroni despite our small 
sample, the underpowering of our results would have been even greater and the likelihood of a Type II error would have been very high.

\section{Measures \\ Dyadic Coping Inventory (DCl)}

This 37-item questionnaire (range 1 "very rarely" to 5 "very often") assesses stress communication and dyadic coping as perceived by (1) each partner about their own coping (what I do when I am stressed and what I do when my partner is stressed), (2) each partner's perception of the other's coping (what my partner does when he or she is stressed, and what my partner does when I am stressed), and (3) each partner's view of how they cope as a couple (what we do when we are stressed as a couple) (see Figure S1).

Internal consistency (Cronbach's $\alpha$ ) in our sample ranged between $\alpha=0.64$ and $\alpha=0.97$ for the patient subscales and between $\alpha=0.71$ and $\alpha=0.97$ for the partner subscales.

Psychometrics of the DCI are good. ${ }^{18}$

\section{Hospital Anxiety and Depression Scale (HADS)}

Participants' psychological state was measured using the HADS. This questionnaire was originally developed for use with patients in nonpsychiatric hospitals. ${ }^{31}$ A validated and widely used self-report measure, it assesses individuals' self-perceived levels of depression and anxiety. It can be used to identify patients with elevated levels of symptoms and disorders that may be clinically relevant (cases: HADS anxiety score $>7 /$ HADS depression score $>7) .{ }^{32}$ Internal consistency of the patient questionnaire in our sample was $\alpha=0.85$ for the anxiety scale and $\alpha=0.88$ for the depression scale. Internal consistency of the partner questionnaire was $\alpha=0.76$ for the anxiety scale and $\alpha=0.80$ for the depression scale.

\section{World Health Organization Quality of Life Questionnaire (WHOQOL)-BREF}

The quality of life of patients and partners was assessed with the WHOQOL-BREF, which is not specific to any illness. A questionnaire containing 26 items, it is an instrument used to measure subjective quality of life. It comprises the domains of physical and psychological health, social relationships and environment, and overall quality of life and general health. Internal consistency (Cronbach's $\alpha$ ) in our sample ranged between $\alpha=0.72$ and $\alpha=0.88$ for the scales of the patient questionnaire. Internal consistency for the scales of the partner questionnaire ranged between $\alpha=0.68$ und $\alpha=0.90$.

\section{Statistical analyses}

Description of the sample in terms of sociodemographic data was carried out using descriptive statistics. In respect of sociodemographic data, participants and nonparticipants as well as patients and partners were examined using $t$-tests and $\chi^{2}$ tests.

In order to assess the effect of a subject's role (patient vs partner) on dyadic coping, one-way analyses of variance with repeated measures (or dependent data, respectively) were calculated.

Pearson's correlations were used to calculate the relationship between patients' $\mathrm{FEV}_{1}$ scores and the dyadic coping of patients and partners. Pearson's correlations were also used to calculate the relationship between the quality of life and the dyadic coping of patients and partners.

In order to test whether patients and partners with elevated scores for anxiety and depression (cases) differ in respect of dyadic coping, $t$-tests were calculated for independent samples.

A relationship between psychological distress/quality of life and severity of disease, income, and education level has been described in the literature. ${ }^{33}$ Thus, it might seem possible that the relationships examined in this study (dyadic coping, quality of life, and psychological distress) could be distorted by participants' severity of disease, income level, and education level. For this reason, we used Pearson's correlations to analyze the relationship between patients' and partners' quality of life/psychological distress and their $\mathrm{FEV}_{1}$ score (severity of disease), education level, and income level. Regarding psychological distress, no significant results were found. Further, calculations were made to assess the possible connection between $\mathrm{FEV}_{1}$ value, education level, and income level on the one side, and the quality of life of patient and partner on the other. Two significant correlations were found: between the patient's income level and the patient's life satisfaction regarding their environment $(r=0.359, P<0.05)$, and between the partner's education level and the partner's life satisfaction regarding their environment $(r=0.394$, $P<0.05$ ). No other significant relationships were found linking the severity of disease, income level, or education level of patient and partner with their quality of life.

Because no significant relationships - other than the two specified previously - were found between patients' and partners' quality of life/psychological distress and their $\mathrm{FEV}_{1}$ score (severity of disease), education level, or income level, it may not be assumed that our results were distorted by these variables. As such, it did not appear essential that we employ multivariate methods to test for these variables 
(severity of disease, education level, income level) and we refrained from doing so.

\section{Results}

\section{Participants}

Of the 399 patients contacted, 97 were willing to participate in the study. Of the 97 patients in total who participated in the study, only the 43 whose partner also took part in the study were included in this investigation. Regarding the severity of their disease $\left(\mathrm{FEV}_{1}\right)$, the participants (a recent $\mathrm{FEV}_{1}$ was available for 31 of the 43 participants) did not differ from the nonparticipants (a recent $\mathrm{FEV}_{1}$ was available for 207 of the 356 nonparticipants) $(t=0.17, d f=236, P=0.876)$.

The most important sociodemographic data are summarized in Table 1 . The age of patients (mean $[\mathrm{M}]=68.21$, standard deviation $[\mathrm{SD}]=9.23)$ ranged between 46 and 83 years, and the age of partners $(\mathrm{M}=66.58, \mathrm{SD}=11.08)$ ranged between 43 and 85 years. The average age of patients and partners did not differ significantly $(t=0.21, d f=48.39$, $P=0.835)$. When comparing the age of the participants and the nonparticipants $(\mathrm{M}=70.94, \mathrm{SD}=8.64)$, a narrowly nonsignificant difference was found $(t=1.97, d f=491$, $P=0.05)$.

\section{Information on disease and treatment}

Table 2 shows the most important information on patients' disease and treatment. Three-quarters of the patients received oxygen treatment and had an average $\mathrm{FEV}_{1}$ score of $40.96 \%$. $\mathrm{FEV}_{1}$ scores were only available for patients who received oxygen treatment. Because distinctions of disease stage were made according to GOLD using $\mathrm{FEV}_{1}$ scores, it was only possible to classify patients for whom such scores were available.

\section{Results for dyadic coping \\ Differences in dyadic coping between patients and partners}

Significant results were revealed on three scales (Table 3) when investigating the association between one's role and his or her dyadic coping. Patients' estimates of their partner's stress communication were lower than partners' estimates of patients' stress communication $(F=5.42, d f=1 / 36$, $P<0.05)$.

Patients rated their own delegated dyadic coping (I assume responsibility for tasks and activities that my partner typically does to take the burden off him/her) significantly lower than did partners $(F=25.66, d f=1 / 37$, $P<0.001)$. The results were reversed - and thus consistent with one another - when participants were asked to assess the delegated dyadic coping of their counterpart. Patients rated the delegated dyadic coping of their partners significantly higher than did partners of the patients $(F=21.29$, $d f=1 / 37.12, P<0.001)$.

\section{Relationship between dyadic coping, severity of disease, and quality of life}

In the following sections, the strength of the relationships between variables is indicated using correlation coefficients. Based on Cohen, ${ }^{34}$ the following criteria may be used to assess their effect sizes: $r=0.1$ (small effect), $r=0.3$ (medium effect), and $r=0.5$ (large effect).

Table I Sociodemographic data of patients and partners ( $N=43$ couples)

\begin{tabular}{|c|c|c|c|c|c|}
\hline & & \multicolumn{2}{|c|}{ Patients } & \multicolumn{2}{|c|}{ Partners } \\
\hline & & $\begin{array}{l}\text { Mean } \\
\mathbf{n}\end{array}$ & $\begin{array}{l}\text { Standard deviation } \\
\%\end{array}$ & $\begin{array}{l}\text { Mean } \\
\mathbf{n}\end{array}$ & $\begin{array}{l}\text { Standard deviation } \\
\%\end{array}$ \\
\hline Age in years & & 68.05 & 9.53 & 66.68 & 11.07 \\
\hline \multirow[t]{2}{*}{ Sex } & Female & 14 & 32.6 & 29 & 67.4 \\
\hline & Male & 29 & 67.4 & 14 & 32.6 \\
\hline \multirow[t]{5}{*}{ Current occupation } & Employed & 5 & II.7 & 14 & 32.6 \\
\hline & Unemployed & 2 & 4.7 & 2 & 4.7 \\
\hline & Homemaker & 2 & 4.7 & 3 & 7 \\
\hline & Pensioner & 23 & 53.5 & 22 & 51.2 \\
\hline & Disability recipient & II & 25.6 & 2 & 4.7 \\
\hline \multirow[t]{7}{*}{ School/professional training } & None & I & 2.3 & 0 & 0 \\
\hline & Compulsory education & 10 & 23.3 & 7 & 16.3 \\
\hline & Apprenticeship & 19 & 44.2 & 25 & 58.1 \\
\hline & Swiss “Matura” & 1 & 2.3 & 1 & 2.3 \\
\hline & Technical college & 7 & 16.3 & 5 & 11.6 \\
\hline & University & 2 & 4.7 & 3 & 7 \\
\hline & Other & 2 & 4.7 & 0 & 0 \\
\hline
\end{tabular}


Table 2 Information on patients' disease and treatment at the time of the survey $(\mathrm{N}=43$ patients)

\begin{tabular}{llll}
\hline & & Patients \\
\cline { 3 - 4 } & & $\begin{array}{l}\text { Mean } \\
\mathbf{n}\end{array}$ & $\begin{array}{l}\text { Standard deviation } \\
\%\end{array}$ \\
\hline FEV $^{\text {a }}$ & & 39.42 & 11.58 \\
Therapy & Oxygen & 32 & 74.4 \\
& Inhalation & II & 25.6 \\
GOLD stage & Stage II & 6 & 19.4 \\
& Stage III & 21 & 67.7 \\
Current smoker & Stage IV & 4 & 12.9 \\
& Yes & 4 & 9.3 \\
& No & 35 & 81.4 \\
\hline
\end{tabular}

Notes: ${ }^{\mathrm{F} E E V}$, scores were only available for patients who received oxygen treatment. Because distinctions of disease stage were made according to GOLD

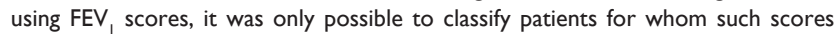
were available.

Abbreviations: $\mathrm{FEV}_{1}$, forced expiratory volume in I second; GOLD, Global Initiative for Chronic Obstructive Lung Disease.

\section{Relationship between dyadic coping and severity of disease}

No significant results were found with respect to correlations between the severity of patients' disease ( $\mathrm{FEV}_{1}$ scores) and the dyadic coping of patients and partners. However, tendencies were revealed regarding participants' assessment of their own stress communication and the negative coping of their partner. Patients with high $\mathrm{FEV}_{1}$ scores rated their own stress communication lower $(r=-0.37, P=0.079)$. Patients with high $\mathrm{FEV}_{1}$ scores also provided lower scores for their partner's negative coping $(r=-0.36, P=0.094)$.

\section{Relationship between patients' assessment of dyadic coping and their quality of life}

Table 4 shows the results regarding the relationship between patients' assessment of dyadic coping and their quality of life.
Patients' own stress communication correlated negatively with their psychological quality of life $(r=-0.35, P<0.05)$, their environment-related quality of life $(r=-0.37, P<0.05)$, and their overall quality of life $(r=-0.33, P<0.05)$. A negative correlation was also found between patients' estimates of their partner's negative coping and patients' social relationships $(r=-0.37, P<0.05)$. Positive correlations were revealed between patients' assessment of their own delegated dyadic coping (patients assuming responsibilities from their partner) and patients' psychological $(r=0.40, P<0.05)$ and physical quality of life $(r=0.32, P<0.05)$. By contrast, negative correlations were found between patients' estimates of their partner's delegated coping (the partner assumes responsibilities from the patient) and patients' psychological quality of life $(r=-0.33, P<0.05)$ and quality of life overall $(r=-0.49, P<0.05)$. A significant positive correlation was found between patients' evaluation of the dyadic coping (satisfaction with dyadic coping) and their social relationships $(r=0.40, P<0.05)$.

\section{Relationship between partners' assessment of dyadic coping and patients' quality of life}

A positive correlation was found between partners' assessment of their own delegated dyadic coping (the partner assumes responsibilities from the patient) and the environment-related quality of life of the patient $(r=0.47$, $P<0.01)$. Positive correlations were also found in respect of common dyadic coping scales, both problem-focused common dyadic coping and emotion-focused common coping. The greater a partner assessed the couple's problem-focused common dyadic coping to be, the more satisfied the patient was with his or her social relationships $(r=0.34, P<0.05)$. There was a significant relationship between the partner's

Table 3 Results of one-way analyses of variance: difference in dyadic coping between patient and partner ( $N=43$ couples)

\begin{tabular}{|c|c|c|c|c|}
\hline & Patient & Partner & $F(d f)$ & $P$ value \\
\hline Total dyadic coping excluding evaluation & 121.28 & 119.24 & $0.4 I(I / 39)$ & 0.527 \\
\hline Own dyadic coping & 51.43 & 52.60 & $0.73(1 / 39)$ & 0.398 \\
\hline Dyadic coping of partner & 53.20 & 50.91 & $1.00(1 / 39)$ & 0.324 \\
\hline Evaluation of dyadic coping & 7.63 & 7.03 & $1.96(1 / 34)$ & 0.170 \\
\hline Own stress communication & 12.38 & 11.25 & $2.49(1 / 39)$ & 0.123 \\
\hline Stress communication of partner & $\mathrm{I} \mathrm{l} .77$ & 13.54 & $5.42(1 / 36)$ & 0.026 \\
\hline Own supportive coping & 17.93 & 18.92 & $2.18(1 / 37)$ & 0.148 \\
\hline Supportive coping of partner & 17.73 & 16.59 & $1.27(1 / 39)$ & 0.267 \\
\hline Own negative coping & 8.32 & 9.05 & $\mathrm{I} .53(\mathrm{I} / 37)$ & 0.224 \\
\hline Negative coping of partner & 8.11 & 8.92 & $1.99(1 / 36)$ & 0.167 \\
\hline Own delegated dyadic coping & 5.87 & 7.89 & $25.66(1 / 37)$ & $<0.001$ \\
\hline Delegated dyadic coping of partner & 8.11 & 5.53 & $21.29(1 / 37)$ & $<0.001$ \\
\hline Problem-focused common coping & 10.91 & 10.80 & $0.06(1 / 34)$ & 0.814 \\
\hline Emotion-focused common coping & 4.83 & 5.03 & $0.25(1 / 34)$ & 0.621 \\
\hline
\end{tabular}


Table 4 Relationship between patients' assessment of dyadic coping and their quality of life $(\mathrm{N}=43)$

\begin{tabular}{|c|c|c|c|c|c|}
\hline \multirow[t]{2}{*}{ Dyadic coping inventory for patient } & \multirow{2}{*}{$\frac{\text { Physical }}{r^{a}}$} & \multirow{2}{*}{$\begin{array}{l}\text { Psychological } \\
r^{\mathrm{a}}\end{array}$} & \multirow{2}{*}{$\begin{array}{l}\text { Social relationships } \\
r^{\mathrm{a}}\end{array}$} & \multirow{2}{*}{$\begin{array}{l}\text { Environment } \\
r^{\mathrm{a}}\end{array}$} & \multirow{2}{*}{$\begin{array}{l}\text { Overall score } \\
r^{a}\end{array}$} \\
\hline & & & & & \\
\hline Total dyadic coping excluding evaluation & 0.16 & -0.08 & 0.14 & -0.18 & -0.03 \\
\hline Own dyadic coping & -0.03 & -0.11 & -0.01 & -0.21 & -0.19 \\
\hline Dyadic coping of partner & 0.18 & -0.11 & 0.09 & -0.14 & 0.05 \\
\hline Evaluation of dyadic coping & 0.24 & 0.03 & $0.40^{\mathrm{b}}$ & -0.01 & 0.13 \\
\hline Own stress communication & -0.22 & $-0.35^{\mathrm{b}}$ & -0.20 & $-0.37^{\mathrm{b}}$ & $-0.33^{b}$ \\
\hline Stress communication of partner & 0.26 & 0.18 & 0.22 & 0.05 & 0.30 \\
\hline Own supportive coping & -0.01 & -0.04 & -0.04 & -0.13 & -0.12 \\
\hline Supportive coping of partner & 0.14 & -0.16 & 0.133 & -0.16 & 0.02 \\
\hline Own negative coping & -0.09 & -0.11 & -0.24 & -0.06 & 0.01 \\
\hline Negative coping of partner & -0.24 & -0.04 & $-0.37^{b}$ & 0.05 & -0.14 \\
\hline Own delegated dyadic coping & $0.40^{\mathrm{b}}$ & $0.32^{\mathrm{b}}$ & 0.25 & 0.09 & 0.24 \\
\hline Delegated dyadic coping of partner & -0.23 & $-0.33^{b}$ & -0.13 & -0.23 & $-0.49^{c}$ \\
\hline Problem-focused common coping & 0.31 & 0.12 & 0.19 & -0.04 & 0.13 \\
\hline Emotion-focused common coping & 0.08 & -0.04 & 0.16 & -0.07 & 0.04 \\
\hline
\end{tabular}

Notes: ${ }^{a} r=0.1$ (small effect); $r=0.3$ (medium effect); $r=0.5$ (large effect); ${ }^{b} P<0.05 ;{ }^{c} P<0.01$.

assessment of the couple's emotion-focused common coping and the psychological quality of life of the patient $(r=0.34$, $P<0.05)$.

Relationship between partners' assessment of dyadic coping and their quality of life

Partners' own negative coping correlated negatively with their physical $(r=-0.34, P<0.05)$ and psychological $(r=-0.43$, $P<0.01)$ quality of life as well as their overall score for quality of life $(r=0.40, P<0.05)$. A positive correlation was found between partners' assessment of their own delegated dyadic coping and their environment-related quality of life ( $r=0.51, P<0.01)$. Additional positive correlations were found between partners' assessment of emotion-focused common coping and their psychological quality of life $(r=0.33$, $P<0.05)$ and social relationships $(r=0.40, P<0.05)$.

\section{Relationship between patients' assessment of dyadic coping and partners' quality of life}

Patients' own stress communication correlated negatively with partners' social relationships $(r=-0.33, P<0.05)$. In addition, patients' own negative coping correlated negatively with their partner's physical quality of life $(r=-0.32, P<0.05)$. Significant positive correlations were found between patients' own delegated coping (the patient assumes responsibilities from the partner) and their partner's physical quality of life $(r=0.40, P<0.05)$ and satisfaction with their quality of social relationships $(r=0.34, P<0.05)$. A negative correlation was found between patients' assessment of their partner's delegated dyadic coping and the partner's quality of social relationships $(r=0-.47, P<0.01)$.

\section{Relationship between dyadic coping} and psychological distress

It was further investigated whether patients and partners with elevated scores for anxiety and depression (cases) differ regarding dyadic coping from patients and partners with lower scores for anxiety and depression. To this end, initial calculations were made to find out how many patients and partners exceeded the HADS cutoff score of $>7$. Thirteen patients and nine partners displayed clinically relevant scores for depression, whereas eleven partners and 15 patients displayed clinically relevant scores for anxiety.

Patients with clinically significant anxiety rated their partner's stress communication lower than did patients with less anxiety $(t=-2.07, d f=34, P<0.05)$. No differences were found among partners when comparing those with elevated anxiety levels with those without elevated anxiety.

Patients with elevated scores for depression provided lower estimates of their partner's stress communication $(t=-2.23, d f=35, P<0.05)$, their own delegated dyadic coping $(t=-2.61, d f=37, P<0.05)$, and problem-focused common dyadic coping $(t=-2.58, d f=34, P<0.05)$. Partners with elevated scores for depression provided higher estimates of both their own negative coping $(t=2.08, d f=37$, $P<0.05)$ and their partner's negative coping $(t=2.56$, $d f=36, P<0.05)$.

\section{Discussion}

The results of this study provide evidence that in couples facing COPD the dyadic coping of the patient differs in part from that of their partner, particularly regarding stress communication and delegated dyadic coping. It also 
revealed that different coping strategies such as high stress communication on the part of patients and high delegated coping on the part of partners (according to patients' assessments) were significantly associated with a lower quality of life among patients and partners. Mirroring earlier studies, ${ }^{18}$ a connection was found between negative dyadic coping and higher depression scores.

Interestingly, partners provided higher estimates of patients' stress communication when both were asked to rate each other's stress communication. Stress communication includes informing one's partner about negative feelings and is often seen as a positive dyadic coping strategy associated with couple satisfaction (unpublished data [Peter-Wight et al] and Acitelli and Badr $^{17}$ ). In our study, however, partners' high estimates of the patient's stress communication may also be considered unfavorable when discussion of illnessrelated difficulties takes up too much space in the relationship. Comparing the stress communication scores of the present study with those in the study by Peter-Wight et al (unpublished data) partners' scores rating their own stress communication and their counterpart's stress communication were found to be lower than comparable values for the general population, whereas patients' stress communication scores were not any higher than usual. One possible explanation for patients' lower estimates of their partner's stress communication is that partners avoid sharing their own problems with patients in an effort to shield them from additional burdens (see Coyne and Smith $^{35}$ ). A partner will often try to prevent the patient from getting upset, as this can aggravate respiratory distress. ${ }^{36}$

Various studies have shown that partners of COPD patients suffer high levels of psychological distress..$^{8,12,14}$ Our study also showed that 13 patients and nine partners displayed clinically significant scores for depression, and eleven patients and 15 partners had elevated scores for anxiety. Partners were thus more affected by anxiety than the patients themselves. In addition, a significant connection was found between patients' expressions of stress and the couple's quality of life. The quality of life of both patient and partner was lower when the patient provided a high estimate of his or her own expressions of stress. As mentioned previously, these results suggest that stress communication should not be viewed solely as a positive dyadic coping strategy.

The results regarding delegated dyadic coping may be similarly interpreted. Both patients and partners stated that the partner took on more from the patient than vice versa. In cases where the patient provided a high estimate of the partner's delegated dyadic coping, both the patient and the partner had a low quality of life. In some cases, the enormous support that the patient receives from the partner may amount to overprotection, diminishing the patient's independence and self-efficacy, and making them feel as if they contribute less to the relationship. ${ }^{10}$ In addition, the new distribution of tasks can lead to changes in patients' social status, which, in turn, can diminish their self-confidence. ${ }^{37}$ In particular, among psychologically distressed patients, well-intentioned displays of support by partners can have a negative effect on the patient. ${ }^{3}$ Partners also had a lower quality of life in cases where the patient stated that the partner took on a lot of extra responsibility. In instances where the partner does a great deal for the patient, the partner often feels overwhelmed, amounting to a reduced quality of life on the part of both the patient and the partner. Consistent with this was the finding of Kramer, ${ }^{38}$ who revealed that a large deficit on the part of patients in taking care of everyday tasks - such as making phone calls, driving, or taking medication - was associated with a lower quality of life on the part of the partner. Balanced social support within a relationship is a key component of couple satisfaction (unpublished data).

Overall, the patient's sense of how much the partner assumes responsibility for that appears to play a crucial role, as no negative correlations were found between partner-assessed delegated dyadic coping and the quality of life of the patient or the partner. Other studies have also found that perceived support plays a bigger role than the actual support received (unpublished data [Peter-Wight et al] and Acitelli and Antonucci ${ }^{39}$ ).

Interestingly, we found no significant correlation between dyadic coping and the severity of patients' disease ( $\mathrm{FEV}_{1}$ scores). In terms of its impact on dyadic coping, this suggests that the subjective perception of the disease plays a larger role than the actual objective severity of the disease. It should be noted, however, that a smaller sample of participants was used to calculate the correlation between $\mathrm{FEV}_{1}$ scores and dyadic coping, because $\mathrm{FEV}_{1}$ scores were only available for oxygen patients. The generalizability of these results is therefore limited.

In the study by Bodenmann et al, ${ }^{19}$ patients with depression perceived less positive and more negative coping on the part of their partners but did not perceive their own dyadic coping any differently from a comparison group. Our results differ from those described by Bodenmann et al. In our study, COPD patients with symptoms of depression assessed their own positive coping lower and their own negative coping higher, when compared with COPD patients without symptoms of depression. Thus, depressed COPD patients appear to differ from other depressed individuals in that they attribute the most negative coping to themselves, not to their partners. 
In addition, COPD patients with symptoms of depression are more likely to perceive an imbalance in provision of support between themselves and their partners, when compared with COPD patients without symptoms of depression. On the other side, depressed partners of COPD patients assessed both their own negative dyadic coping and that of the patient higher, when compared with nondepressed partners of COPD patients. Interestingly, depressed partners did not consider the couple's coping to be unbalanced in the same way the depressed COPD patients did; rather, they simply perceived it as more negative. Here too the results from the depressed partners of COPD patients are only consistent with those of Bodenmann et a ${ }^{19}$ insofar as the depressed partners of COPD patients rated their counterpart's coping as more negative. However, the depressed partners of COPD patients also provided higher estimates of their own negative coping when compared with nondepressed partners of COPD patients.

In respect of anxiety, no differences in dyadic coping were found, other than diminished stress communication among partners of patients with clinically relevant levels of anxiety.

\section{Limitations}

Due to a low response rate (24.3\%), the results of the present study are limited in their generalizability. The participants did not differ from nonparticipants regarding $\mathrm{FEV}_{1}$ score or age. However, the possibility that the two groups differed regarding other variables cannot be ruled out, meaning that the results might only apply to the participants. In addition, the results only refer to COPD patients in a committed relationship, which further restricts their generalizability. The study's sample size is also relatively small in terms of the number of couples $(\mathrm{N}=43)$ who participated. One reason for the low response rate is likely the outpatient setting. Inpatients are more likely to complete and return questionnaires, because their decision to participate or not may be checked in person. ${ }^{40}$ In contrast to other studies with higher response rates, ${ }^{12}$ the patients were not invited to participate in person; rather, their participation was anonymously requested in a letter sent by mail, and they were not offered any reward or compensation for joining the study. A further reason for the low response rate may be its status as a "partner study", requiring a mutual willingness to participate on the part of both patients and their partners. Unfortunately, this requirement was not met by a sizable number of couples who could have participated. In addition, the subjects of our study belong to a hard-to-reach population for survey studies.
They met several criteria associated with low response rates: advanced age, poor health and related limitations, relatively low education level, and low income. ${ }^{41,42}$ Further, individuals who have a chronic disease that researchers wish to study may be affected by survey fatigue..$^{43}$ Indeed, the patients we approached had already been interviewed with questionnaires in previous studies.

Another limitation of the data consists of the fact that $\mathrm{FEV}_{1}$ scores were not available for all patients. The results that included severity of disease only relate to the patients receiving oxygen therapy and thus cannot be generalized.

Except for two results regarding environment-related quality of life (patients' income, partners' education level), no significant correlations were found between participants' quality of life/psychological distress and their severity of disease, income, or education level. The existing association with patients' income and partners' education level might affect the validity of the results for environment-related quality of life. Due to the relatively small sample size and the complex data structure - featuring dependent data within couples and men and women in either role (patient or partner) - the researchers refrained from applying multivariate analyses.

Finally, the cross-sectional design of our study rules out drawing conclusions as to the direction of the causal relationship between dyadic coping and quality of life or psychological distress, respectively. It remains an open question whether dyadic coping influences quality of life and psychological distress or vice versa. This point would need to be investigated in depth by a prospective study.

\section{Conclusion}

The results of the study suggest that partners of COPD patients strongly support the patients yet receive little support themselves. In cases where patients feel they are unable to take care of tasks they once did, this correlates with a lower quality of life on the part of both patients and their partners. Such patients also have higher scores for depression. Among partners, negative dyadic coping is associated with higher scores for depression.

From a clinical perspective, it appears that partners of COPD patients should be integrated into care. Partners provide crucial support to patients yet must bear considerable burdens themselves. The strains of a chronic disease like COPD should also be viewed from a couple's perspective. Regular screening of patients and partners could help identify highly distressed individuals early on, as the strain of the chronic disease can have a negative effect on couples' 
relationship and quality of life. Dyadic coping may be seen as a buffer to that effect. Therapeutic interventions to improve dyadic coping include (1) improving stress communication, (2) developing different options for supportive, delegated, and common dyadic coping, and (3) installing and stabilizing new forms of dyadic coping. ${ }^{2,44}$ The coping-oriented couple approach proposed by Bodenmann may offer a valuable way to support couples with chronic disease in an attempt to strengthen mutual dyadic coping resources. Perceived imbalances should be addressed and corresponding adjustments to the dyadic coping strategy considered, as these may help safeguard individual and dyadic homeostasis. Providing couples professional support regarding managing the tasks of everyday life is also crucial to their handling of the disease. Rather than allowing all the responsibility to fall to partners, couples' tasks should be appropriately divided between patients, partners, and professional support persons.

\section{Acknowledgment}

The present study was financed and supported by the Zurich Lung League (http://www.lungenliga-zh.ch), which made the study possible.

\section{Disclosure}

The authors report no conflicts of interest in this work.

\section{References}

1. Bodenmann G. Stress und coping bei paaren [Stress and coping in couples]. Göttingen, Germany: Hogrefe; 2000. German.

2. Bodenmann G. Dyadic coping - a systemic-transactional view of stress and coping among couples: theory and empirical findings. Eur Rev Appl Psychol. 1997;47:137-140.

3. Hagedoorn M, Kuijer RG, Buunk BP, et al. Marital satisfaction in patients with cancer: does support from intimate partners benefit those who need it the most? Health Psychol. 2000;19:274-282.

4. Kayser K. Enhancing dyadic coping during a time of crisis: a theory-based intervention with breast cancer patients and their partners. In: Revensond TA, Kayser K, Bodenmann G, editors. Couples couping with stress: Emerging perspectives on dyadic coping. Washington, DC: American Psychological Association; 2005:175-194.

5. Revenson TA, Abraido-Lanza AF, Majerovitz SD, Jordan C. Couples coping with chronic illness: what's gender got to do with it? In: Revenson TA, Kayser D, Bodenmann G, editors. Couples couping with stress: Emerging perspectives on dyadic coping. Washington, DC: American Psychological Association; 2005:137-256.

6. Dakof GA, Taylor SE. Victims' perception of social support: what is helpful for whom? J Pers Soc Psychol. 1990;58:80-89.

7. Gillissen A. Die chronisch-obstruktive lungenerkrankung (2.Auflage) Chronic obstructive pulmonary disease (second edition). Bremen, Germany: Uni-Med; 2003. German.

8. Ehlert U, editor. Verhaltensmedizin [Behavioral health]. Berlin, Germany: Springer; 2002. German.

9. Pforte A. COPD - chronisch-obstruktive lungenerkrankungen und komplikationen [COPD - chronic obstructive pulmonary disease and complications]. Wien, Austria: Blackwell Wissenschafts-Verlag Berlin; 2002. German.
10. Cannon C, Cavanaugh J. Chronic Illness in the context of marriage: a systems perspective of stress and coping in chronic pulmonary disease. Fam Syst and Health. 1998;16:401-418.

11. Büchi S, Brändli $\mathrm{O}$, Klingler $\mathrm{K}$, et al. Stationäre rehabilitation bei patienten mit chronisch obstruktiver lungenerkrankung (colk): effekte auf körperliche leistungsfähigkeit, psychisches wohlbefinden und lebensqualität [Rehabilitation among patients with chronic obstructive pulmonary disease (copd): effects on physical functioning, psychological well-being, and quality of life]. Schweizerische Medizinische Wochenschrift. 2000;130:135-142. German.

12. Kühl K, Schurmann W, Rief W. Mental disorders and quality of life in COPD patients and their spouses. Int J Chron Obstruct Pulmon Dis. 2008;3:727-736.

13. Hamacher J, Linnemann T, Baumhäkel M, et al. Asthma, COPD, partnerschaft und sexualität [Asthma, COPD, partnership, and sexuality]. In: Ligner H, Schultz K, Schwartz F, eds. Volkskrankheit asthma/COPD. Bestandsaufnahmen und perspektiven [Widespread disease asthma/COPD. Inventories and perspectives]. Heidelberg, Germany: Springer Medizin Verlag; 2007:161-168. German.

14. Booth S, Silvester S, Todd C. Breathlessness in cancer and chronic obstructive pulmonary disease: using a qualitative approach to describe the experience of patients and carers. Palliat Support Care. 2003;1: 337-344.

15. Gysels MH, Higginson IJ. Caring for a person in advanced illness and suffering from breathlessness at home: threats and resources. Palliat Support Care. 2009; 7:153-162.

16. Ashmore JA, Emery CF, Hauck ER, MacIntyre NR. Marital adjustment among patients with chronic obstructive pulmonary disease who are participating in pulmonary rehabilitation. Heart Lung. 2005;34: 270-278.

17. Acitelli LK, Badr HJ. My Illness or our illness? Attending to the relationship when one partner is ill. In: Revenson TA, Kayser K, Bodenmann G, editors. Couples coping with stress: emerging perspectives on dyadic coping. Washington, DC: American Psychological Association; 2005:121-136.

18. Bodenmann G. Dyadisches Coping Inventar (DCI) [Dyadic Coping Inventory]. Bern, Switzerland: Huber; 2008. German.

19. Bodenmann G, Widmer K, Charvoz L, Brandbury T. Differences in individual and dyadic coping in depressed, non-depressed and remitted persons. J Psychopathol Behav Assess. 2004;26:75-85.

20. Manne S, Badr H. Intimacy and relationship processes in couples' psychosocial adaptation to cancer. Cancer. 2008;112(11 Suppl): 2541-2555.

21. Schokker MC, Links TP, Luttik ML, Hagedoorn M. The association between regulatory focus and distress in patients with a chronic disease: the moderating role of partner support. Br J Health Psychol. 2010;15: 63-78.

22. Revenson T, Kayser K, Bodenmann G, editors. Couples couping with stress: emerging perspectives on dyadic coping. Washington, DC: American Psychological Association; 2005.

23. Schwarzer C, Busch B. Dyadic coping with retirement in elderly couples. Appl Psychol Newsletter. 2005;17:13-23.

24. Bodenmann G, Plancherel B, Beach SRH, et al. Effects of copingoriented couples therapy on depression: a randomized clinical trial. $J$ Consult Clin Psychol. 2008;76:499-954.

25. GOLD: Global Initiative for Chronic Obstructive Lung Disease. Global strategy for the diagnosis, management, and prevention of chronic obstructive pulmonary disease; 2006. Available at: http://www.who.int/ respiratory/copd/GOLD_WR_06.pdf. Accessed on October 21, 2011.

26. Bortz J. Statistik für sozialwissenschaftler [Statistics for social scientists]. Berlin, Germany: Springer-Lehrbuch; 1993. German.

27. Perneger TV. What's wrong with Bonferroni adjustments. BMJ. 1998;316:1236-1238.

28. Shinichi N. A farewell to Bonferroni: the problems of low statistical power and publication bias. Behav Ecol. 2004;15:1044-1045.

29. Matthew D. Arguments for rejecting the sequental Bonferroni in ecological studies. Forum. 2003;100:403-405. 
30. Bjelland I, Dahl AA, Haug TT, Neckelmann D. The validity of the hospital anxiety and depression scale. An updated literature review. J Psychosom Res. 2002;52:69-77.

31. Zigmond AS, Snaith RP. The hospital anxiety and depression scale. Acta Psychiatr Scand. 1983;67:361-370.

32. Angermeyer M, Kilian R, Matschinger H. WHOQOL-100 und WHOQOL-BREF. Handbuch für die Deutschsprachige version der WHO-instrumente für die erfassung von lebensqualität [WHOQOL100 and WHOQOL-BREF. Manual for the German-language version of the WHO instruments for measuring quality of life]. Göttingen, Bern, Toronto, Seattle: Hogrefe; 2000. German.

33. Lampert T, Kroll L. Die messung des sozioökonomischen status in sozialepidemiologischen studien [The measurement of socio-economic status in socio-epidimiological studies]. Berlin, Germany: Springer; 2009. German.

34. Cohen J. Statistical Power Analysis for the Behavioral Sciences. 2nd ed. Hillsdale, NJ: Erlbaum; 1988.

35. Coyne J, Smith D. Couples coping with a myocardical infarction: a conceptual perspective on wives' distress. J Pers Soc Psychol. 1991;61:404-412.

36. Sexton DL, Munro BH. Impact of a husband's chronic illness (COPD) on the spouse's life. Res Nurs Health. 1985;8:83-90.

37. Wigal JK, Creer TL, Kotses H. The COPD self-efficacy scale. Chest. 1991;99:1193-1196.

38. Kramer BJ. Marital history and the prior relationship as predictors of positive and negative outcomes among wife caregivers. Fam Relat. $1993 ; 42: 367-375$.
39. Acitelli LK, Antonucci TC. Gender differences in the link between marital support and satisfaction in older couples. J Pers Soc Psychol. 1994;67:688-698.

40. Mehnert A, Müller D, Lehmann C, Koch U. Die Deutsche version des NCCN Distress-Thermometers [German version of the NCCN Distress Thermometer]. Zeitschrift für Psychiatrie, Psychologie und Psychotherapie. 2006;54:213-223. German.

41. Sheldon H, Rasul F. Increasing response rates among BME and other hard to reach groups. Picker Institute Europe; 2007. Available from: http://www.nhssurveys.org/Filestore/documents/Increasing_response_ rates_stakeholder_consultation_v6.pdf. Accessed on October 21, 2011.

42. Leinsalu M, Kaposvár iC, Kunst A. Is income or employment a stronger predictor of smoking than education in economically less developed countries? A cross-sectional study in Hungary. BMC Public Health. 2011;11:97.

43. Munir F, Khan H, Yarker J, et al. Health behaviours among older and younger workers with chronic illness. Patient Educ Couns. 2009;77: 109-115.

44. Bodenmann G. New themes in couple therapy: the role of stress, coping and social support. In Hahlweg K, Grawe M, Baucom D, editors Enhancing couples: the shape of couples therapy to come. Cambridge, MA: Hogrefe; 2010:142-156. 


\section{Supplementary figure}

\section{Dyadic coping inventory (DCl)}

This scale is designed to measure how you and your partner cope with stress. Please indicate the first response that you feel is appropriate. Please be as honest as possible.

Please respond to any item by ticking the appropriate box that fits your personal situation.

There are no wrong answers.

This section is about how you communicate your stress to your partner.

\begin{tabular}{|c|c|c|c|c|c|c|}
\hline & & $\begin{array}{c}\text { Very } \\
\text { rarely }\end{array}$ & Rarely & $\begin{array}{l}\text { Some- } \\
\text { times }\end{array}$ & Often & $\begin{array}{l}\text { Very } \\
\text { often }\end{array}$ \\
\hline 1. & $\begin{array}{l}\text { I let my partner know that I appreciate his/her practical } \\
\text { support, advice, or help. }\end{array}$ & $\square$ & $\square$ & $\square$ & $\square$ & $\square$ \\
\hline 2. & $\begin{array}{l}\text { I ask my partner to do things for me when I have too much to } \\
\text { do. }\end{array}$ & $\square$ & 口 & 口 & $\square$ & $\square$ \\
\hline 3. & $\begin{array}{l}\text { I show my partner through my behaviour when I am not doing } \\
\text { well or when I have problems. }\end{array}$ & $\square$ & $\square$ & $\square$ & 口 & D \\
\hline 4. & $\begin{array}{l}\text { I tell my partner openly how I feel and that I would appreciate } \\
\text { his/her support. }\end{array}$ & $\square$ & $\square$ & $\square$ & 口 & $\square$ \\
\hline
\end{tabular}

This section is about what your partner does when you are feeling stressed.

\begin{tabular}{|c|c|c|c|c|c|c|}
\hline & & $\begin{array}{l}\text { Very } \\
\text { rarely }\end{array}$ & Rarely & $\begin{array}{l}\text { Some- } \\
\text { times }\end{array}$ & Often & $\begin{array}{l}\text { Very } \\
\text { often }\end{array}$ \\
\hline 5. & My partner shows empathy and understanding to me. & $\square$ & $\square$ & $\square$ & $\square$ & $\square$ \\
\hline 6. & My partner expresses that he/she is on my side. & $\square$ & $\square$ & $\square$ & $\square$ & $\square$ \\
\hline 7. & My partner blames me for not coping well enough with stress. & $\square$ & $\square$ & $\square$ & $\square$ & $\square$ \\
\hline 7. & $\begin{array}{l}\text { My partner helps me to see stressful situations in a different } \\
\text { light. }\end{array}$ & $\square$ & $\square$ & $\square$ & $\square$ & $\square$ \\
\hline 9. & $\begin{array}{l}\text { My partner listens to me and gives me the opportunity to } \\
\text { communicate what really bothers me. }\end{array}$ & $\square$ & 口 & $\square$ & ב & $\square$ \\
\hline 10. & My partner does not take my stress seriously. & $\square$ & $\square$ & $\square$ & $\square$ & $\square$ \\
\hline 11. & $\begin{array}{l}\text { My partner provides support, but does so in an unwilling } \\
\text { and unmotivated manner. }\end{array}$ & $\square$ & $\square$ & $\square$ & $\square$ & $\square$ \\
\hline 12. & $\begin{array}{l}\text { My partner takes on things that I normally do in order to help } \\
\text { me out. }\end{array}$ & $\square$ & $\square$ & $\square$ & $\square$ & $\square$ \\
\hline 13. & $\begin{array}{l}\text { My partner helps me analyze the situation so that I can better } \\
\text { face the problem. }\end{array}$ & $\square$ & 口 & $\square$ & 口 & $\square$ \\
\hline 14. & When I am too busy, my partner helps me out. & $\square$ & $\square$ & $\square$ & 口 & $\square$ \\
\hline 15. & When I am stressed, my partner tends to withdraw. & $\square$ & $\square$ & $\square$ & $\square$ & $\square$ \\
\hline
\end{tabular}

Figure SI (Continued) 
This section is about how your partner communicates when he/she is feeling stressed.

16. My partner lets me know that he/she appreciates my practical
support, advice, or help.

This section is about what you do when your partner makes known his/her stress.

\begin{tabular}{|c|c|c|c|c|c|c|}
\hline & & $\begin{array}{l}\text { Very } \\
\text { rarely }\end{array}$ & Rarely & $\begin{array}{l}\text { Some- } \\
\text { times }\end{array}$ & Often & $\begin{array}{l}\text { Very } \\
\text { often }\end{array}$ \\
\hline 20. & I show empathy and understanding to my partner. & $\square$ & $\square$ & $\square$ & $\square$ & $\square$ \\
\hline 21. & I express to my partner that I am on his/her side. & $\square$ & $\square$ & $\square$ & $\square$ & $\square$ \\
\hline 22. & I blame my partner for not coping well enough with stress. & $\square$ & 口 & $\square$ & $\square$ & $\square$ \\
\hline 23. & $\begin{array}{l}\text { I tell my partner that his/her stress is not that bad and help } \\
\text { him/her to see the situation in a different light. }\end{array}$ & $\square$ & $\square$ & $\square$ & ב & $\square$ \\
\hline 24. & $\begin{array}{l}\text { I listen to my partner and give him/her space and time to } \\
\text { communicate what really bothers him/her. }\end{array}$ & $\square$ & 口 & $\square$ & $\square$ & $\square$ \\
\hline 25. & I do not take my partner's stress seriously. & $\square$ & 口 & $\square$ & $\square$ & $\square$ \\
\hline 26. & When my partner is stressed I tend to withdraw. & $\square$ & $\square$ & $\square$ & $\square$ & $\square$ \\
\hline 27. & $\begin{array}{l}\text { I provide support, but do so in an unwilling and unmotivated } \\
\text { manner because I think that he/she should cope with his/her } \\
\text { problems on his/her own. }\end{array}$ & $\square$ & $\square$ & $\square$ & $\square$ & $\square$ \\
\hline 28. & $\begin{array}{l}\text { I take on things that my partner would normally do in order to } \\
\text { help him/her out. }\end{array}$ & $\square$ & $\square$ & $\square$ & $\square$ & $\square$ \\
\hline 29. & $\begin{array}{l}\text { I try to analyze the situation together with my partner in an } \\
\text { objective manner and help him/her to understand and change } \\
\text { the problem. }\end{array}$ & $\square$ & $\square$ & $\square$ & $\square$ & $\square$ \\
\hline 30. & $\begin{array}{l}\text { When my partner feels he/she has too much to do, I help } \\
\text { him/her out. }\end{array}$ & $\square$ & $\square$ & $\square$ & 口 & $\square$ \\
\hline
\end{tabular}

Figure SI (Continued) 
This section is about what you and your partner do when you are both feeling stressed.

31. We try to cope with the problem together and search for
solutions.
32. We engage in a serious discussion about the problem and think
through what has to be done.

This section is about how you evaluate your coping as a couple.

36. I am satisfied with the support I receive from my partner and
the way we deal with stress together. $\begin{aligned} & \begin{array}{c}\text { Very } \\ \text { rarely }\end{array} \\ & \text { 37. Iarely }\end{aligned} \begin{aligned} & \begin{array}{c}\text { Some- } \\ \text { times }\end{array} \\ & \text { I am satisfied with the support I receive from my partner and I } \\ & \text { find as a couple, the way we deal with stress together is } \\ & \text { effective. }\end{aligned}$

Figure SI Dyadic coping inventory.

\section{Publish your work in this journal}

The International Journal of COPD is an international, peer-reviewed journal of therapeutics and pharmacology focusing on concise rapid reporting of clinical studies and reviews in COPD. Special focus is given to the pathophysiological processes underlying the disease, intervention programs, patient focused education, and self management protocols.
This journal is indexed on PubMed Central, MedLine and CAS. The manuscript management system is completely online and includes a very quick and fair peer-review system, which is all easy to use. Visit http://www.dovepress.com/testimonials.php to read real quotes from published authors 